\title{
Evaluation of balance and fear of falling in elderly individuals before and after senile cataract surgery
}

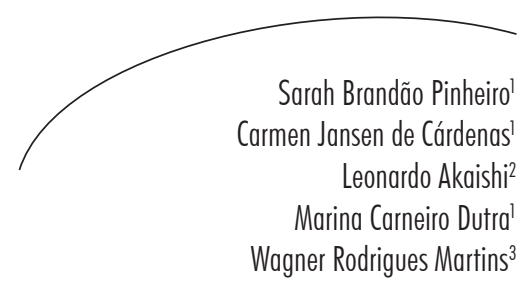

Abstract

Introduction: During aging there is a close relationship between visual deficits, imbalance and falls, and eye surgery can be an efficient treatment option for elderly persons. Objective: Evaluate the influence of visual conditions on patients suffering from senile cataract with increasing imbalance. Method: A descriptive and analytical study using a quantitative longitudinal cohort technique was conducted. The study included 30 individuals who were evaluated before and 30 and 60 days after surgery. The Mini Mental State Examination (MMSE), Berg Balance Scale (BBS), Short Physical Performance Battery (SPPB), International Falls Efficacy Scale adapted for Brazil (FES-I) and a medical history questionnaire were used to collect data. Statistical analysis involved the Chi-squared, Student's t and Mann-Whitney tests. Values of $p<0.05$ were considered significant. Results: The SPPB found that of 15 elderly women, $13(87 \%)$ achieved moderate performance of the lower limbs while the performance of two $(13 \%)$ remained poor, after 60 postoperative days. The FES-I revealed that three (20\%) elderly persons were mildly worried about falls 60 days post-surgery. Of the 15 elderly male subjects evaluated by BBS, before and at 30 and 60 days after surgery, one (7\%), managed to maintain some balance but needed assistance; while 14 (93\%) maintained good balance. The SPPB found that the performance of five elderly persons $(33 \%)$ was moderate and that of nine $(67 \%)$ was good. Conclusion: Senile cataract surgery had positive preventative effects on lower limb performance, balance and fear of falling among the elderly studied, preventing the falls and fractures that are common during aging.

\footnotetext{
Universidade Católica de Brasília, Escola de Medicina, Programa de Pós-graduação em Gerontologia. Brasília, Distrito Federal, Brasil.

2 Instituto de Catarata de Brasília, Unidade de Cirurgia, Departamento Médico. Brasília, Distrito Federal, Brasil.

3 Universidade de Brasília, Faculdade de Ceilândia, Curso de Fisioterapia. Brasília, Distrito Federal, Brasil.

Correspondence

Sarah Brandão Pinheiro

E-mail: sarah.brandao@gmail.com
}

Key words: Postural Balance; Accidental Falls; Elderly; Senile Cataract. 


\section{INTRODUCTION}

Aging is a universal biological process in most living creatures, especially human beings. It is not limited to the simple passage of time but is a dynamic, progressive and irreversible process, characterized by different biological, psychic and social manifestations that occur during the lives of individuals. ${ }^{1-3}$

In this context, longevity is often accompanied by losses that occur throughout life. One of the first systems to be impacted by physiological aging is the sensory system, notably vision. Elderly people with visual impairment tend to suffer from postural control deficit, functional impairment and increased risk of falls. ${ }^{4}$

The operation of the visual system has the function of providing the central nervous system (CNS) with data about the position and movement of parts of the body relative to objects in the surrounding physical environment, including people or objects in motion. With aging, the visual system undergoes a series of changes, such as a reduction in acuity and the field of vision, diminished contrast sensitivity, a reduction in dark adaptation, and alterations in the absorption of light and depth perception. ${ }^{5}$

The visual system may be compromised in a cumulative and progressive manner by means of metabolic and environmental damage, characterizing the intimate relationship between vision and senescence. Associated with the physiological changes to vision that occur during aging, chronic eye diseases corroborate the decline in the visual ability of the elderly. ${ }^{6}$ Visual impairment is usually defined by the visual acuity value, which is part of the functional vision of the indivídual. ${ }^{7}$ This is the ideal value that characterizes loss of vision and is used as a criterion to define visual impairment by the World Health Organization (WHO). ${ }^{8}$

Among the causes of loss of visual acuity loss is the cataract, the most significant etiological factor for blindness and visual impairment in the world, accounting for approximately $50 \%$ of cases in developed and developing countries and leading to a decrease in visual acuity, contrast sensitivity and color perception. ${ }^{9,10}$ Yet a cataract is a condition that can be treated easily and safely. Ultrasound modulation surgery, for example, has produced great benefits for ophthalmic practice and also for patients. In such surgery, cataract removal is performed with precise incisions in the crystalline lens, allowing the surgeon a high degree of confidence and reproducibility. ${ }^{11}$

Studies have identified a close relationship between visual impairment, imbalances, falls and hip fractures among the elderly. ${ }^{12}$ This pathology - the cataract - leads to a reduced perception of surfaces, depth, distance, body positions and contrast, thus affecting mobility and the ability to maintain postural control of the elderly. The ability to maintain balance and postural control is important for the proper functional performance of the activities of daily living (ADLs) by an individual. Elderly people with balance disorders are more likely to suffer falls and their consequences. ${ }^{13}$ It is estimated that the prevalence of complaints of imbalance in the population over 65 years of age is as high as $85 \%$, and the condition is associated with several etiologies, such as: degeneration of the vestibular system; decreased visual acuity, the ability to perform visual accommodation and persecution movements; proprioceptive changes; musculoskeletal deficit; cerebellar atrophy; a decrease in mechanisms of attention and reaction. These conditions contribute to balance disorders in the elderly and therefore increase the chance of falls. ${ }^{14}$

In this context, fractures from falls account for approximately $70 \%$ of accidental deaths in people over 75 years. ${ }^{15}$ The precise identification of the cause of an imbalance must involve a clinical evaluation aimed at the patient's complaint and related diseases, as well as a comprehensive evaluation of the systems involved in balance and their possible limitations. ${ }^{16}$ 
Therefore, given that a cataract may alter balance and lead to falls, and that eye surgery can be an effective alternative for the elderly, significantly improving their physical and functional parameters, the present study aimed to evaluate the balance and fear of falls in elderly persons of both genders who suffered from senile cataract, both before and after eye surgery was performed, through different assessment tests and tools.

\section{METHOD}

A descriptive and analytical study using a quantitative longitudinal cohort approach was carried out between January and July 2014. The study was approved by the Ethics Research Committee of the Universidade Católica de Brasília (the Catholic University of Brasília) (CEP/UCB), CAAE: 108221513.9.0000.0029, in accordance with Resolution $n^{\circ} 466 / 2012$ of the National Health Council. The volunteers received detailed information about the aim and procedures of the study and took part only after signing a Free and Informed Consent Form (FICF).

The field of research of the study was the Instituto de Catarata de Brasília (the Brasilia Cataract Institute) (ICB), located at SEP/S - EQ 715/915 Sul, Conjunto A, Bloco C, Asa Sul, Brasília, in the Distrito Federal (Federal District) of Brazil.

Sample selection was performed by crosssectional, observational and individualized inquiry, taking into account the availability of the individuals to participate in the study. It was estimated that with 15 patients of each gender, the study would have a power of $80 \%$ to detect clinically important differences between genders ( 60 days compared to baseline) using Berg Balance Scale (BBS) scores, assuming a mean difference in score between the groups of 2.3 points with a combined standard deviation of 2.1 points (obtained from published data), ${ }^{1}$ for a significance level of $5 \%$. Thus, the sample consisted of 30 elderly patients with pure and mixed bilateral senile cataract, diagnosed clinically by an ophthalmologist from the ICB, who had not undergone surgical treatment. The statistical calculation to set the sample size was based on previous studies. ${ }^{13}$ A pilot study was conducted with four elderly men and six elderly women in order to calibrate the protocol and adjust the instruments.

The inclusion criteria used were that individuals should be aged over 60 years, of either gender, with senile cataract and physical conditions that allowed the proposed assessments to be performed. Older people who did not achieve a score of 27 points on the Mini Mental State Examination were excluded (MMSE); ${ }^{17}$ as well as those whose mobility was dependent on aids; those with a low level of education; vestibular disorders; recent reports of fractures; the presence of painful symptoms or edema of the lower limbs (LL); orthopedic and/or rheumatic diseases in the lower limbs and patients who were taking medications that interfered with their balance, such as antihypertensive, antiarrhythmic, diuretics and vasodilator medication and drugs against hyperthyroidism.

The present study involved a risk of falling or imbalance during the tests. To avoid such an event, a researcher remained next to the elderly persons during the time of the tests, providing safety in clinical exams. To avoid the fatigue of the elderly persons, a rest period of five minutes was established between each test, and individuals continued to the next examination only when fully recovered.

In relation to the evaluation procedures, the appointments of the volunteers were scheduled only after they had undergone a medical consultation. They were instructed to return to the study location to be re-evaluated on two occasions. At the first appointment an assessment was carried out between one and seven days before eye surgery was performed, with the MMSE applied to assess cognitive function in order to ascertain whether the individual would be able to participate in the study. After this first step, the elderly persons were evaluated by the BBS, ${ }^{18}$ to evaluate the functional 
balance of individuals with static and dynamic balance deficit. The BBS is often used to determine risk factors for loss of independence and falls in the elderly. This scale assesses balance across 14 items common to daily life, each of which has five alternative responses ranging from 0-4 points, giving a maximum score of 56 points. The lower the score achieved by the individual, the greater his or her risk of falling. ${ }^{18}$

On a third occasion, LLs performance was evaluated using the Short Physical Performance Battery (SPPB) instrument, ${ }^{19}$ assessing the balance, gait and strength of the lower limbs using three feet positions: (1) in parallel, (2) with the hallux resting against the medial edge of the heel and (3) with the hallux resting against the back edge of the heel. One point was attributed if the first or second test was performed in 10 seconds or less $(\leq)(10$ ") and zero points were awarded if the first or second test took longer than 10 seconds $(>)\left(10^{\prime \prime}\right)$. In the third test, the points awarded varied from 0 for $<3$ ", 1 for between 3 " and 9.99" and 2 if $\geq 10 " .{ }^{19}$ For gait evaluation, a stopwatch was used to record the time that a person took to move along a corridor of three meters (round trip), repeating the route twice. The scores of the instrument ranged from: 0 , when unable; 1 if took $>6.52 "$ " 2 if the time required was between 4.66" and 6.52"; 3 if the time was between 3.62" and $4,65 "$ and 4 if the time was $<3.62 "$. The muscle strength of the LLs was also evaluated using the time that the elderly persons took to get up from a chair ( $45 \mathrm{~cm}$ in height with armrest) with the upper limbs (UL) crossed over their chests, repeating the test five consecutive times. The scores varied according to the time taken: 0 when incapable of performing the action; 1, if >16.7"; 2 between 13.7" and 16.69"; 3 for a time between 11.2" and $13.69 "$ and 4 if $<11.19 "$.

The total SPPB score allows values between 0 and 12 points and represents the performance of the LLs of the elderly through the following grading: 0 to 3 where incapable or perform very poorly; 4 to 6 points for poor performance; 7-9 points for moderate performance and 10 to 12 points if performed well. ${ }^{20}$

Finally, the elderly were assessed by the Falls Efficacy Scale - International adapted for Brazil (FES-I-Brazil). ${ }^{21}$ The choice of this scale as a tool to measure the fear of falling in communitydwelling elderly persons was based on its measuring properties, internal consistency (a-Cronbach $=0.96$ ) and test-retest reliability (ICC=0.96). The FES-IBrazil includes questions regarding concern over the possibility of falling and involves 16 activities, with respective scores of one to four. The total score can range from 16 (not at all concerned) to 64 (very concerned), with up to 16 points representing an absence of concern; up to 32 mild concern; up to 48 moderate concern and up to 64 extreme concern. ${ }^{21}$

The tests were performed on Mondays, Thursdays and Fridays in the morning, over a period of seven months. The time of evaluation was chosen based on the availability of the patient and the researcher. However, it was observed that in the morning the patients felt positive about factors that influence vision such as light, sleep and nutritional factors.

The two subsequent meetings were scheduled in the postoperative period, 30 and 60 days after bilateral surgery (the patient underwent the surgery in one eye and following an average of 7 to 15 days the other eye was operated on), and lasted approximately 30 minutes.

The baseline characteristics, or those before senile cataract surgery, of the two groups (men and women) were compared using the Chi-squared test or Fisher's exact test, in the event that the expected frequencies were less than five, for the qualitative variables. The Student-t test was used for the quantitative variables with Gaussian distribution and the Mann-Whitney test for those without Gaussian distribution. The Chi-squared test or Fisher's exact test were used to assess the association between the occurrence of fear of falling and physical activity. 
Longitudinal disorders were tested independently for each group (elderly men and women), using a mixed effect linear regression model with random intercept, with an adjustment for baseline values and age, for each of the outcome variables (BBS, SPPB and FES-I-Brazil). It should be considered that the linear regression model is not a common linear model, but one of mixed effects where the intra-individual changes (over time) and the changes among individuals (for each gender) are evaluated. As age is a confounding variable, influencing the effects, it must be controlled in the statistical model even if it later interferes in the results. The change in each dependent variable outcome was defined as: values at 30 days less the baseline values and the values at 60 days less the baseline values.

The independent variables in the model were considered to be the effect of time (30 to 60 days), age and as a covariate the value of the outcome at baseline. The main focus of the analysis was to check, for each outcome, if the mean values at 30 and 60 days differed significantly from the mean values at baseline. When the overall $p$-value of the linear effect over time was less than 0.05, comparisons at 30 and 60 days compared to baseline were tested. Analyses were performed with the use of the Statistical Analysis System version 9.3. The results were also expressed in absolute/ relative values for the categorical variables.

\section{RESULTS}

The study sample consisted of 30 elderly persons, 15 women (50\%) and 15 men (50\%). Table 1 shows the characteristics of the sample before senile cataract surgery.

Table 1. Baseline characteristics of study participants. Brasília, Federal District, 2014.

\begin{tabular}{lccc}
\hline \multicolumn{1}{c}{ Variable } & \multicolumn{2}{c}{ Groups } & \\
\hline Educational level* & Elderly women $(\mathrm{n}=15)$ & Elderly men $(\mathrm{n}=15)$ & p-value \\
Primary School & $3(20.0)$ & $0(0.0)$ & \\
High School & $9(60.0)$ & $5(33.3)$ & \\
Higher education & $3(20.0)$ & $10(66.7)$ & 0.4642 \\
Has suffered falls?* & & & \\
No & $6(40.0)$ & $8(53.3)$ & 0.2557 \\
Yes & $9(60.0)$ & $7(46.7)$ & \\
Fear of falls?* & & & \\
No & $8(53.3)$ & $11(73.3)$ & 0.4561 \\
Yes & $7(46.7)$ & $4(26.7)$ & \\
Overweight/obesity* & & & \\
No & $7(46.7)$ & $10(66.7)$ & 0.0092 \\
Yes & $8(53.3)$ & $71.1( \pm 6.2)$ & 0.3969 \\
Age** & $65.6( \pm 6.6)$ & $52.3( \pm 7.8)$ & 0.0110 \\
BBS** & $54.7( \pm 1.49)$ & $8.6( \pm 1.8)$ & 0.0354 \\
SPPB** & $6.8( \pm 1.5)$ & $21.3( \pm 4.9)$ & \\
FES-I-Brazil** & $26.5( \pm 9.3)$ & & \\
\hline
\end{tabular}

*Values expressed in $\mathrm{n}(\%) ; * *$ mean and standard-deviation; BBS= Berg Balance Scale; SPPB= Short Physical Performance Battery; FES-I-Brazil= Falls Efficacy Scale International adapted to Brazil. 
Table 2 shows that no elderly persons displayed improvement in balance before and after the surgical procedure according to the BBS test. All retained a score of between points 41 and 56, representing independent individuals with proper functional balance, or in other words, ideal for ADLs. From the SPPB, it was observed that of the 15 elder persons before surgery, seven had poor (47\%) and eight had good LL performance (53\%). After 30 days of surgery, it was observed that 12 elderly persons $(80 \%)$ had a score of between 7 and 9 points, or in other words moderate performance, and three $(20 \%)$ had a score of between 4 and 6 points, indicating poor LL performance. At 60 days after surgery it was observed that of the 15 elderly persons, 13 (87\%) achieved moderate performance and two (13\%) poor performance. Assessing the FES-I-Brazil test, it was observed that before senile cataract surgery four elderly women $(27 \%)$ had a score of between 32 and 48 points, indicating a mild concern about falling and $11(73 \%)$ had a score of 16 and 32 points, indicating they were not at all concerned about falls. After 30 days of surgery, it was observed that these values were maintained, in other words of the 15 elderly persons, four $(27 \%)$ had mild concern about falling and 11 (73\%) had no concern. At 60 days after surgery, it was observed that three (20\%) elderly persons continued to have a mild concern over the falls and $12(80 \%)$ had no concern.

When observing the difference between genders (Table 2), of the 15 elderly subjects evaluated by the BBS before surgery and at 30 and 60 days after surgery, one elderly person maintained a score of between 21 and $40(7 \%)$, or in other words this patient maintained some balance, but required assistance, and 14 (93\%) had scores of 41-56, which characterizes individuals with good balance or who are independent for the performance of ADLs. Assessing the SPPB test results, it was observed that before surgery, one elderly person $(7 \%)$ had a score of between 4 and 6 , or poor LL performance; ten elderly subjects $(67 \%)$ had a score of between 7 and 9 , indicating moderate performance and four elderly persons $(26 \%)$ had a score of 10 to 12 , which indicates good LL performance. After 30 days of surgery, it was observed that the LL performance of one elderly (7\%) remained poor, nine elderly $(60 \%)$ persons had moderate performance and five (33\%) had good performance. After 60 days of surgery, it was observed that five elderly persons (33\%) had moderate performance and nine (67\%) had good SPPB results. Regarding the FES-I-Brazil test, there was no variation in the results before and at 30 and 60 days after surgery. Of the 15 elderly persons, one ( $7 \%$ ) had mild concern about falling and $14(93 \%)$ had no concern. 
Table 2. Analysis of effect of eye surgery on the parameters of static and dynamic balance, performance of lower limbs and fear of falls by groups of elderly persons after 30 and 60 days. Brasília, Federal District, 2014.

\begin{tabular}{lcccccc}
\hline \multicolumn{1}{c}{ Variable } & Basal* & $\begin{array}{c}\text { Time (days) } \\
\text { Change at } 30 \\
\text { days* }\end{array}$ & $\begin{array}{c}\text { Change at } 60 \\
\text { days* }\end{array}$ & $\begin{array}{c}\text { Linear } \\
\text { effect }\end{array}$ & 30 x Basal & $60 \times$ Basal \\
\hline BBS & $54.73( \pm 0.38)$ & $0.87( \pm 0.16)$ & $1.07( \pm 0.16)$ & 0.1746 & - & - \\
\hline SPPB & $6.80( \pm 0.39)$ & $0.53( \pm 0.22)$ & $1.20( \pm 0.22)$ & 0.0160 & 0.0304 & $<0.0001$ \\
\hline FES-I-Brazil & $26.53( \pm 2.40)$ & $-1.20( \pm 0.94)$ & $-3.53( \pm 0.94)$ & 0.0798 & - & - \\
\hline & & Group of Elderly Men $(\mathrm{n}=15)$ & & 0.0036 \\
\hline BBS & $52.27( \pm 2.01)$ & $0.33( \pm 0.38)$ & $1.33( \pm 0.38)$ & 0.0326 & 0.3979 & - \\
\hline SPPB & $8.60( \pm 0.46)$ & $0.27( \pm 0.19)$ & $0.53( \pm 0.19)$ & 0.0933 & - & - \\
\hline FES-I-Brazil & $21.27( \pm 1.26)$ & $-0.07( \pm 0.79)$ & $-0.53( \pm 0.79)$ & 0.6646 & - & - \\
\hline
\end{tabular}

*Values expressed in means and standard-deviation; \#p-values calculated using linear regression model of mixed effects with random intercept; BBS= Berg Balance Scale; SPPB= Short Physical Performance Battery; FES-I-Brazil= Falls Efficacy Scale International adapted to Brazil.

The results show that the linear trend over time of the BBS results of the group of elderly women did not significantly differ from zero $(p=0.1746)$, indicating that the average values of BBS at 30 and 60 days did not differ from the mean BBS value at baseline (figure 1). In contrast, this linear trend differed significantly from zero $(p=0.0326)$ among elderly men. It was also verified that the mean value of BBS at 30 days did not differ significantly from baseline $(p=0.3979)$, while at 60 days there was an increase of 1.33 points in the BBS, significantly higher than baseline ( $p=0.0036$ ).

In terms of SPPB, it was observed that in the group of elderly men the linear trend over time did not significantly differ from zero ( $p=0.0933)$, indicating that the mean SPPB values at 30 and 60 days did not significantly differ from the mean basal SPBB value (figure 2). However, among elderly women this linear trend differed significantly from zero $(p=0.0160)$. The mean value of SPPB at 30 days showed a significant increase of 0.53 points ( $p=0.0304)$ from the baseline, while at 60 days there was an increase of 1.20 points in the SPPB value, which was significantly higher than the first evaluation $(p<0,0001)$.

With respect to the FES-I-Brazil, it can be seen that in both groups the linear trend over time did not differ significantly from zero $(p=0.0798, p=$ 0.6646 , respectively), indicating that the mean FES-I-Brazil values at 30 and 60 days did not differ from the initial FES-I-Brazil mean (baseline) (figure 3). 


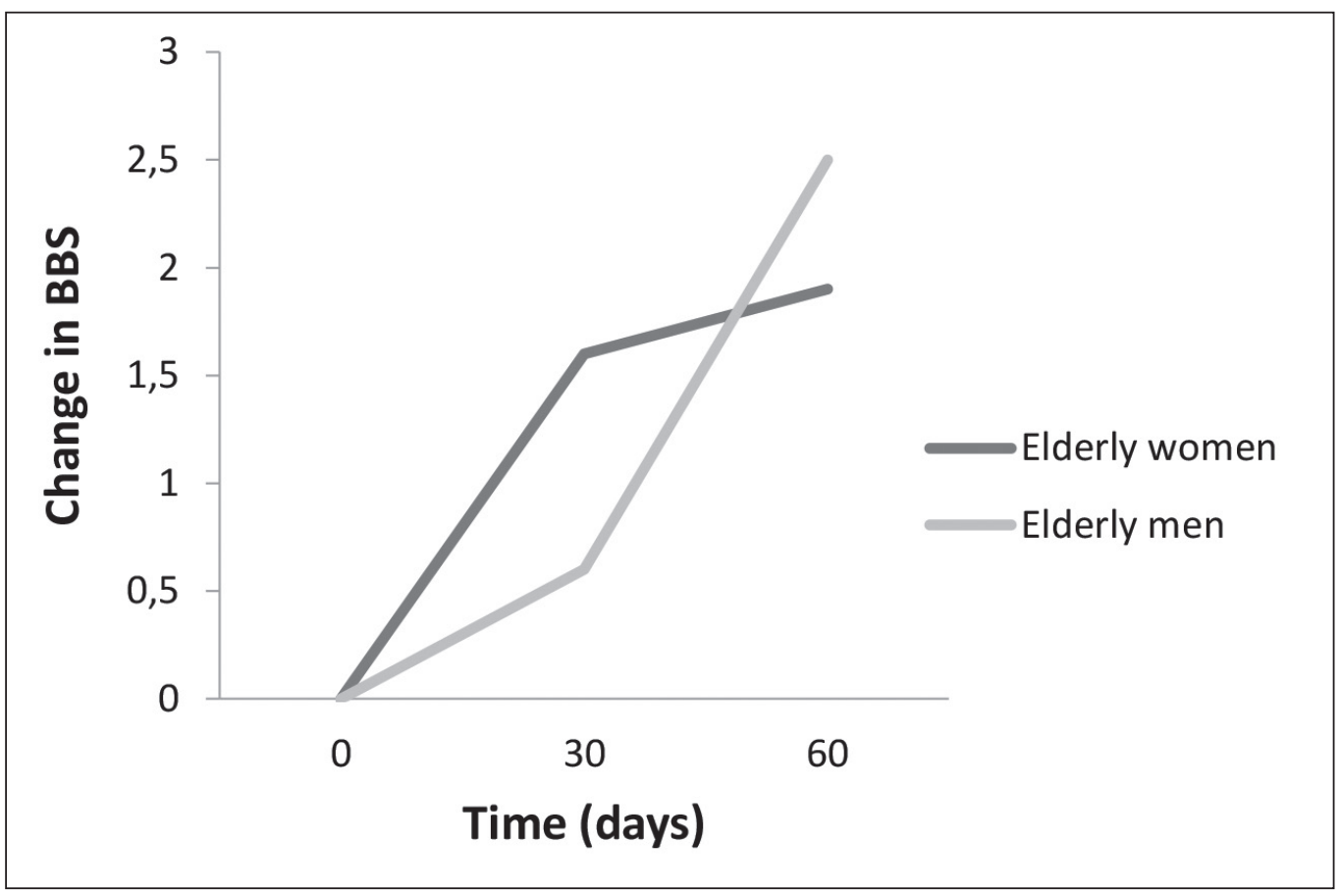

Figure 1. Analysis of effect before and after eye surgery on the parameters of static and dynamic balance (Berg Balance Scale - BBS) by elderly group. Brasília, District Federal, 2014.

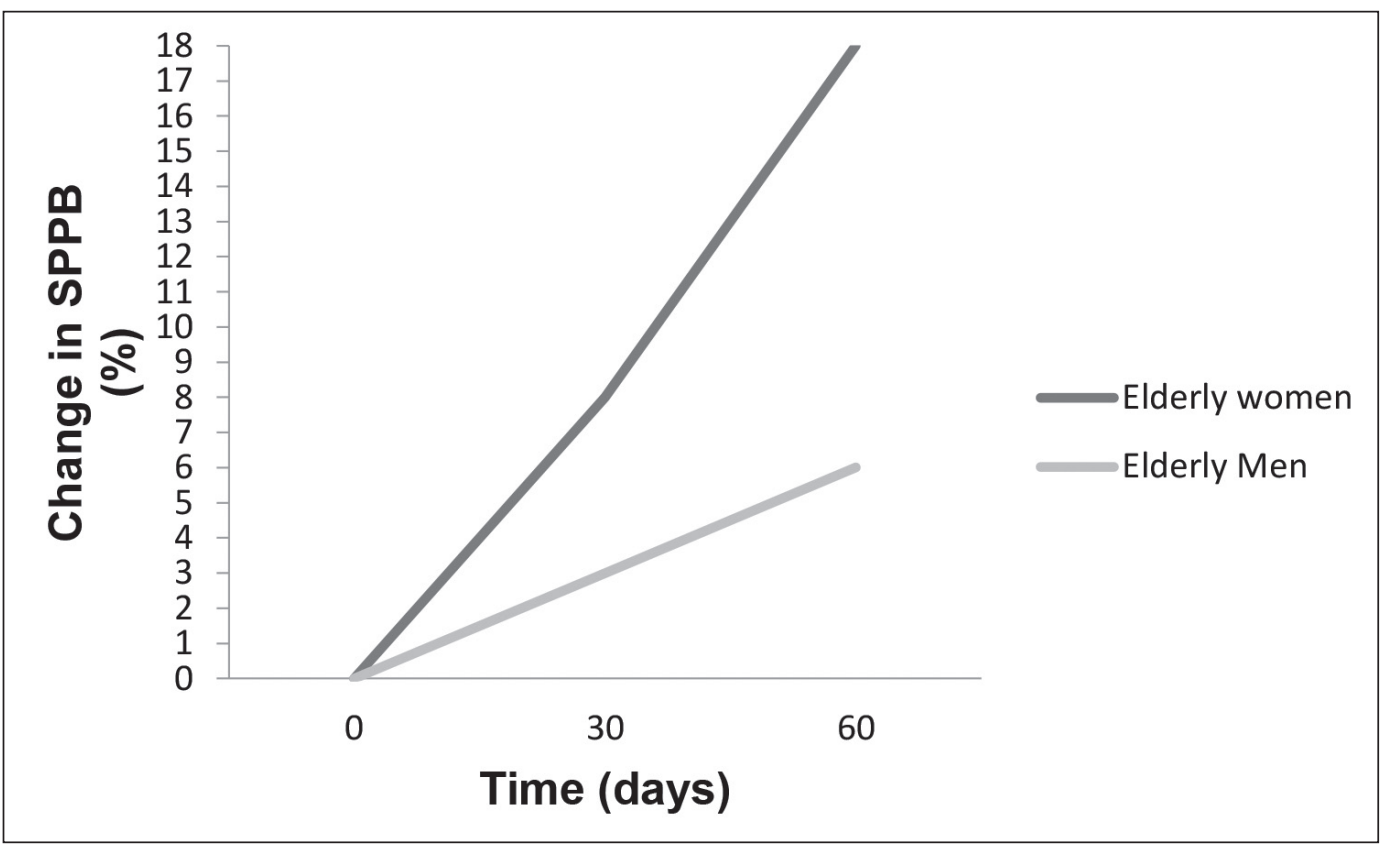

Figure 2. Analysis of effect before and after eye surgery on lower limb performance parameters (Short Physical Performance Battery test - SPPB) by elderly group. Brasília, Federal District, 2014. 


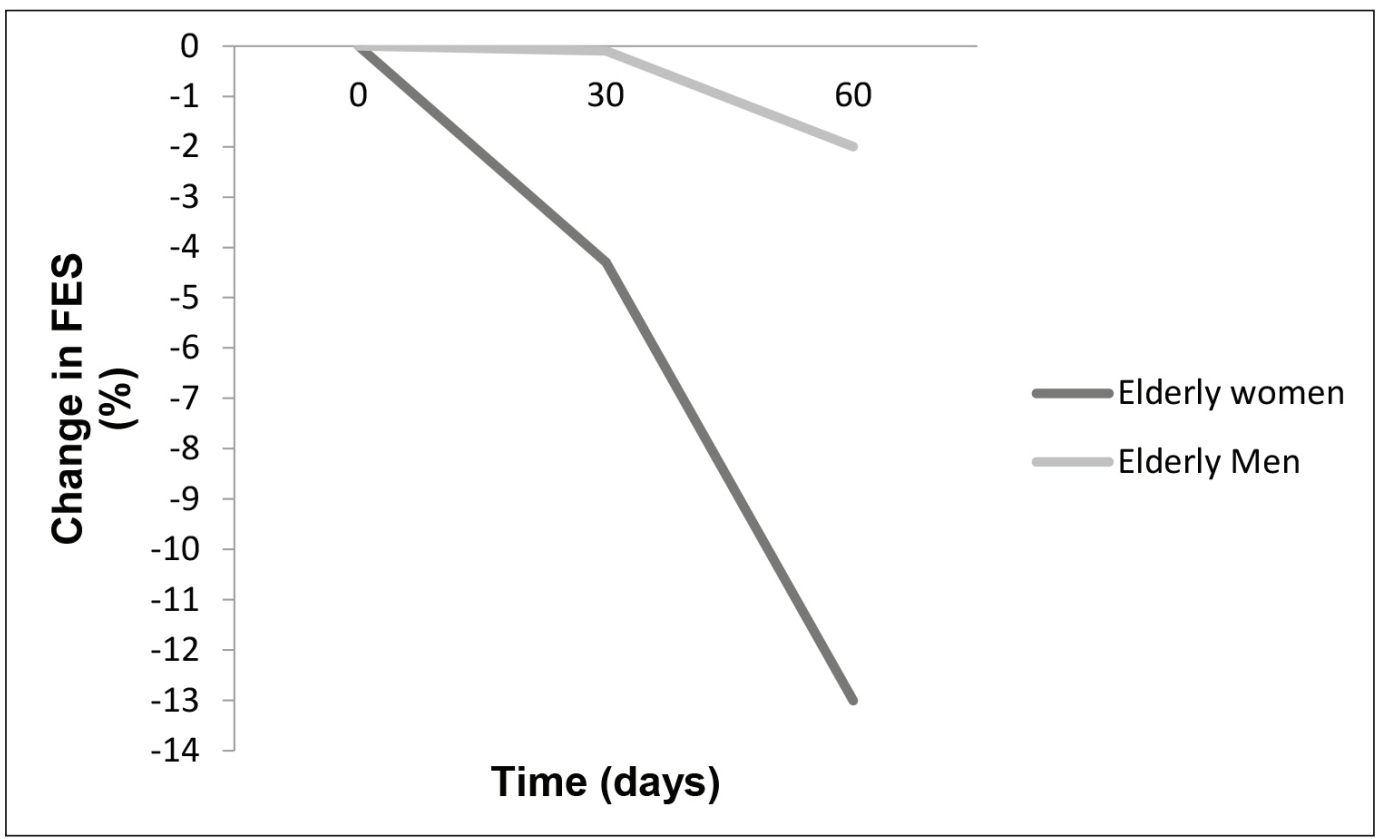

Figure 3. Analysis of effect before and after eye surgery on the parameters of fear of falls (Falls Efficacy Scale International adapted to Brazil - FES-I-Brazil) by elderly group. Brasília, Federal District, 2014.

Figures 1, 2 and 3 show the mean values for the elderly women and elderly men versus the variables throughout the follow-up period.

\section{DISCUSSION}

According to the results of this study, BBS values did not differ significantly over time for elderly women, in other words, cataract surgery did not improve - or worsen - their static and dynamic balance. Among all the elderly women the BBS test proved that over a short period of time (60 days after surgery) cataract surgery did not contribute to postural stability; results which are not concordant with other studies..$^{22,23}$

However, the BBS values of the elderly men increased 1.33 points after 60 days, which was significantly higher than baseline $(p=0.0036)$. This result was expected as the elderly men were older than the older women and by the fact that the elderly men seek medical services later that older women. ${ }^{24}$ The older the individual the greater difficult in balancing he or she will have and therefore, as the elderly men were older they would be expected to have lower results related to static and dynamic balance; these results are consistent with other studies. ${ }^{22,23}$

Elderly patients with visual impairment due to cataracts develop other compensatory mechanisms to perform their ADL. However, three tasks proposed by the BBS test - reach forward, stand with one foot in front of the other and stand on one foot - have been found to be more suitable for detecting functional changes in balance, as they are more difficult for elderly persons to perform. ${ }^{18}$

Therefore, the result of the present study showed that there was a correlation between decreased visual acuity (the ability to see within a normality of $90 \%$ of healthy vision) and the performance of the elderly individual in the BBS test. Studies have found a similar association between visual impairment and functional balance disorders in the elderly, including through the application of other tests, such as the Performance Oriented Mobility Assessment and the Tinetti Balance test. 25,26 
In terms of the SPPB results, the linear trend over time did not differ significantly for the elderly men, with the mean SPBB values at 30 and 60 days not differing from the mean SPPB value at baseline. In other words, for the group of elderly men, the SPPB test revealed there were no statistically significant benefits from cataract surgery in relation to balance and LL strength. In the group of elderly women, however, this linear trend was significant, as it was found that the mean SPPB value after 30 days showed a significant increase compared to baseline, while the value at 60 days was significantly greater than baseline $(p<0.0001)$. This fact proves that cataract surgery improved balance in older women 30 and 60 days after surgery.

It was also observed that the elderly women maintained routines of physical activity more often than elderly men, demonstrating the probable improvement of lower limb strength identified by the SPPB. In other words, of the 15 elderly women, nine practiced physical activities between three and seven days a week; of the 15 elderly men, nine practiced physical activities between two and five days a week; in other words, less frequently than the elderly women. Studies indicate that regular physical activity can improve balance in the elderly, as noted in the SPPB test. ${ }^{27}$ Physical activity reduces the risk of falls as it improves cognitive activities and promotes a strengthening of the locomotor system. ${ }^{22}$

Fear of falling is associated with physical decline -including visual and functional declines affecting the ability to perform ADLs and alterations in the balance and gait of the elderly. Tinetti et al. ${ }^{28}$ suggested that the effectiveness of balance control in relation to falls through specific tests assesses performance more fully than subjective and dichotomous questions about fear of falling. This study ${ }^{28}$ is based on a composite sample of older adults, showing independence in their routines, $35 \%$ of whom practiced some kind of physical activity.
The results of the FES-I-Brazil test did not differ significantly in statistical terms over time, meaning that the mean values of the FES-I-Brazil test at 30 and 60 days remained linear with respect to baseline. These results show that in this study cataract surgery did not significantly improve fear of falls among individuals.

Some authors have reported that even elderly individuals who had not fallen may have fear of falling. ${ }^{29}$ Some studies show that the prevalence of fear of falling in the elderly, regardless of gender, ranges from $20 \%$ to $85 \%$. In this sense, fear may be a protective factor as elderly persons take more care not to expose themselves to risk, yet it may also be a risk when it causes limitations and insecurity. ${ }^{30}$ In this study, it was also noted is that, among the 15 elderly women, nine had experienced more than one fall and of those, five were afraid of falling again. Among the 15 elderly men, seven had fallen at least once and of those three were afraid of relapses. Arfken et al. ${ }^{31}$ demonstrated the relationship between fear of falling and the number of falls suffered by an individual, which supports the results obtained in this study.

It was also found that there was no statistically significant relationship between elderly individuals who had suffered falls and were afraid of falling with schooling and overweight/obesity. However, Cordeiro $^{32}$ demonstrated the relationship between balance disorders in patients with diabetes mellitus type II, all of whom were overweight/obese. Studies have shown that there is a relationship between the education of elderly persons and falls, or in other words, the higher the level of education, the lower the risk of falling, as more educated older people tend to seek information on, for example, how to achieve a good quality of life in old age..$^{33,34}$

In summary, this study was notable due to its easy reproducibility and low cost, although it was limited by its focus on the elderly population who retained mobility without the use of walking aids. It is also likely that the low statistical significance 
observed for some results was due to the short assessment period proposed. Thus, the scientific community should be aware of the importance of new research related to this subject, involving longer study periods.

\section{CONCLUSION}

This study demonstrated that senile cataract surgery improved static and dynamic balance, assessed by the Berg Balance Scale, especially among elderly men; it significantly improved the performance of the lower limbs, measured by the Short Physical Performance Battery, notably among older women; but had no effect in relation to the fear of falling among all the participants in this study, probably due to the short intervals when reassessment took place (30 and 60 days).

The contributions of this study include the inference that early diagnosis of visual impairment significantly benefits the elderly and prevents future functional losses arising from this and other consequences, such as falls, as well as showing that senile cataract surgery can have positive effects on balance, especially among elderly men, functioning as an important tool for reducing falls, which are common in the physiological process of aging.

\section{REFERENCES}

1. Freitas EV, Py L, Cançado FAXC, Doll J, Gorzoni ML. Tratado de Geriatria e Gerontologia. $2^{a}$ ed. Rio de Janeiro: Guanabara Koogan; 2011

2. Motta AB. Envelhecimento e sentimento do corpo. In: Minayo MCS, Coimbra CEA Jr. Antropologia, saúde e envelhecimento. Rio de Janeiro: Fiocruz; 2002. p. 37-50.

3. Rebelatto JR, Morelli JGS. Fisioterapia Geriátrica: a prática da assistência ao idoso. $2^{\mathrm{a}}$ ed. Barueri: Manole; 2007.

4. Menezes RL, Bachion MM. Condições visuais autorrelatadas e quedas em idosos institucionalizados. Rev Bras Oftalmol 2012;71(1):23-7.

5. Perracini MR, Fló CM. Funcionalidade e envelhecimento. Rio de Janeiro: Guanabara Koogan; 2011.

6. Luiz LC, Rebelatto JR, Coimbra AMV, Ricci NA. Associação entre déficit visual e aspectos clínicofuncionais em idosos da comunidade. Rev Bras Fisioter 2009;13(5):444-50.

7. Berger S, Porell F. The association between low vision and function. J Aging Health 2008;20(5):504-25.

8. Luiz L.C. et al. Associação entre déficit visual e aspectos clínico-funcionais em idosos da comunidade. Revista Brasileira de Fisioterapia. v. 13, n. 5, p. 444-50, 2009. Organização Mundial de Saúde. ISBN 13009789242560817. 2010. Disponível em: http://who.int/bookorders/anglais/detart1. jsp? sesslan $=1 \& \operatorname{codlan}=2 \& \operatorname{cod} \operatorname{col}=24 \& \operatorname{codcch}=8283$
9. Temporini ER, Kara JN, José NK, Holzchuh N. Popular beliefs regarding the treatment of senile cataract. Rev Saúde Pública 2012;36(3):343-9.

10. Tideiksaar R. As quedas na velhice: prevenção e cuidados. $2^{a}$ ed. São Paulo: Andrei; 2010.

11. Giménez GR. Buscando la excelencia en la cirugía de la catarata. Arch Soc Esp Oftalmol 2007;82(4):254.

12. Lord SR, Smith ST, Menant JC. Vision and falls in older people: risk factors and intervention strategies. Clin Geriatr Med 2010;26(4):569-81.

13. Macedo BG, Pereira LSM, Rocha FL, Castro ANBV. Association between funcional vision, balance and fear of falling in older adults with cataracts. Rev Bras Geriatr Gerontol 2012;15(2):265-74.

14. Figueiredo KM, Lima KC, Guerra RO. Instrumentos de avaliação do equilíbrio corporal em idosos. Rev Bras Cineantropom Desempenho Hum 2007;9(4):408-13.

15. Fuller GF. Falls in the elderly. Am Fam Physician 2000;61(7):2159-68.

16. Simoceli L, Bittar RMS, Bottino MA, Bento RF. Perfil diagnóstico do idoso portador de desequilíbrio corporal: resultados preliminares. Rev Bras Otorrinolaringol 2010;69(6):772-7.

17. Nitrini R, Caramelli P, Bottino CMC, Damasceno BP, Brucki SMD, Anghinah R. Diagnóstico de doença de Alzheimer no Brasil: critérios diagnósticos e exames complementares. Arq Neuropsiquiatr 2005;63(3A):713-9. 
18. Miyamoto ST, Lombardi I Júnior, Berg KO, Ramos LR, Natour J. Brazilian Version of Berg Balance Scale. Braz J Med Biol Res 2004;37(9):1411-21.

19. Nakano MM. Versão brasileira da Short Physical Performance Battery - SPPB: adaptação cultural e estudo da confiabilidade [dissertação]. Campinas: Universidade Estadual de Campinas; 2007.

20. Sposito G, Diogo MJD, Cintra FA, Neri AL, Guariento ME, De Sousa MLR. Relações entre o bem-estar subjetivo e a funcionalidade em idosos em seguimento ambulatorial. Rev Bras Fisioter 2010;14(1):81-9.

21. Camargos FF, Dias RC, Dias JF, Freire MT. Cross-cultural adaptation and evaluation of the psychometric properties of the Falls Efficacy ScaleInternational Among Elderly Brazilians (FES-IBRAZIL). Rev Bras Fisioter 2010;14(3):237-43.

22. Barnett A, Smith B, Lord SR, Williams M, Baumand A. Community based group exercise improves balance and reduces falls in at-risk older people: a randomized controlled trial. Age Ageing 2011;32(4):407-14.

23. Overstall PW, Exton-Smith AN, Imms FJ, Johnson AL. Falls in the elderly related to postural imbalance. Br Med J 1977;1(6056):261-4.

24. Caldas CP, Veras RP, Motta LB, Lima KC, Kisse CBS, Trocado CVM, et al. Rastreamento do risco de perda funcional: uma estratégia fundamental para a organização da Rede de Atenção ao Idoso. Ciênc Saúde Coletiva 2013;18(12): 3495-506.

25. Huang M, Burguess R, Weber M, Greenwald N. Performance of balance impaired elders on three balance tests under two visual conditions. J Geriatr Phys Ther 2006;29(1):5-9.

26. Owsley C, McGwin G Jr. Association between visual attetion and mobility in older adults. J Am Geriatr Soc 2004;52(11):1901-6.
27. Rebelatto JR, Calvo JI, Orejuela JR, Portillo JC. Influência de um programa de atividade física de longa duração sobre a força muscular manual e a flexibilidade corporal de mulheres idosas. Rev Bras Fisioter 2006;10(1):127-32.

28. Tinetti ME, Richman D, Powell L. Falls efficacy as a measure of fear of falling. J Gerontol 1990;45(6):239-43.

29. Scheffer AC, Schuurmans MJ, Van de Rooij SE. Fear of falling: measurement strategy, prevalence, risk factors and consequences among older persons. Age Ageing 2008;37(1):19-24.

30. Zijlstra GA, Van Haastregt JC, Van Eijk JT, Van Rossum E, Stalenhoef PA, Kempen GI. Prevalence and correlates of fear of falling, and associated avoidance of activity in the general population of community-living older people. Age Ageing 2007;36(3):304-9.

31. Arfken C, Lach H, Birge S, Miller J. The prevalence and correlates of fear of falling in elderly persons living in the community. Am J Public Health 1994 84(4):565-70.

32. Cordeiro RC. Caracterização clínico-funcional do equilíbrio em idosos portadores de Diabetes Mellitus do tipo II [dissertação]. São Paulo: Universidade Federal de São Paulo; 2001.

33. Custódio EB, Malaquias JJ, Voos MC. Relação entre cognição (função executiva e percepção espacial) e equilíbrio de idosos de baixa escolaridade. Fisioter Pesqui 2010;17(1):46-51.

34. Pereira F, Fernandes A, Miguel T. Fatores, riscos e consequências de quedas em idosos institucionalizados. In: $6^{\circ}$ Congresso Internacional de Saúde, Cultura e Sociedade [Internet]; 28-29 maio 2010; Chaves, Portugal. Chaves: Escola Superior de Enfermagem Dr. Timóteo Montalvão Machado; 2010 [acesso em 10 de fevereiro de 2014]. p. 1-12. Disponível em: https:// bibliotecadigital.ipb.pt/handle/10198/4437. 